\title{
Simulation of the rotary-screw vehicle motion on snow
}

\author{
Yan Arlauskas ${ }^{1}$, Yuri Molev ${ }^{1,}{ }^{*}$, Valentina. Obrezkova ${ }^{1}$, and Valery Naumov ${ }^{2}$ \\ ${ }^{1}$ Nizhny Novgorod State Technical University, 603950 N.Novgorod, Minin st., 24, Russia \\ ${ }^{2}$ Bauman Moscow State Technical University, 105005 Moscow, Baumanskaya 2-ya, 5, Russia
}

\begin{abstract}
The article presents the determination of oscillation parameters of the rotor-screw vehicle during motion on rough terrain. The study presented the dynamics of off-road vehicle movement. The dependence of the vehicle vibration characteristics on the mover geometry and suspension parameters was found. The experiment with the vehicle was performed. Analysis of the research results allows to conclude that the use of the suspension increases speed of the rotary-screw vehicle by $1.5-2.5$ times. The developed model and obtained results will be useful in design of allterrain vehicles.
\end{abstract}

\section{Introduction}

The task of transforming the Arctic region into a leading strategic resource base of the country with a developed transport infrastructure is enshrined in "Foundations of the State Policy of the Russian Federation in the Arctic until 2020". At the same time, due to low density of the population and small volumes of freight traffic, the creation and development of a wide network of roads and railways in this area seems impractical. Therefore, the main task of ensuring high mobility of the population can be solved only with the all-terrain vehicles.

Currently, there are about 100 types of all-terrain vehicles in the world capable of carrying out transport and technological operations in the Arctic all year round. However, the movement on unprepared surface causes health disorder of passengers and rapid deterioration of the vehicle. In addition, the vibrations of all-terrain vehicle is a source of increased structural noise during the movement. If a lot of scientific research is devoted to oscillation of the most common types of movers, such as wheeled and tracked $[1,2,3,4]$, then due attention has not been paid to the problems of oscillations of the rotary-screw mover. This fact is primarily due to the fact that the rotary-screw mover was considered as a technological mover that moves at low speeds $[5,6,7]$. Therefore, the study of the rotary-screw mover interaction with the supporting surface is an important scientific task for vibration reduction of the vehicle.

\footnotetext{
* Corresponding author: moleff@yandex.ru
} 


\section{Methods}

It is proposed to consider the oscillations of the body of the rotary-screw vehicle, arising from the vertical and angular movements of the rotors during motion on uneven ground [8, $9,10,11,12]$. The disturbing forces from the rotors are transmitted through the suspension to the body of the vehicle, which makes forced vertical and longitudinal-angular oscillations.

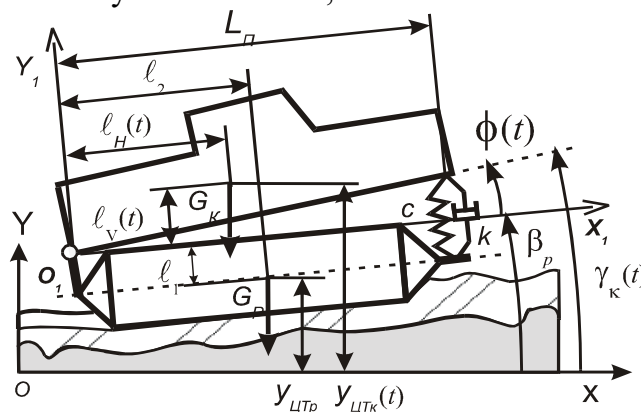

Fig. 1. Modeling of the rotary-screw vehicle body oscillation

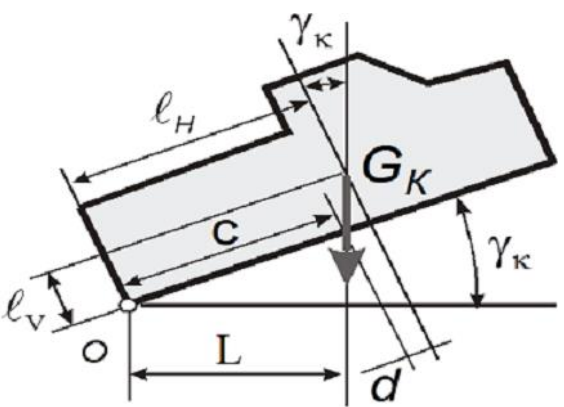

Fig. 2. To the determination of the moment from the gravity force of the rotary-screw vehicle body

The longitudinal angular oscillations of the body can be described using the differential equation of the rotational moment of the body movement relative to the swing axis of the rotors $\mathrm{O}[13,14,15,16]$ (Fig. 1)

$$
J_{0} \ddot{\varphi}=M_{G_{k}}-c L^{2} \varphi-k L^{2} \dot{\varphi},
$$

where $\varphi, \dot{\varphi}, \ddot{\varphi}$ - respectively, angular displacement, velocity and acceleration of the body relative to the rotors (in the moving coordinate system $X_{1} O_{1} Y_{1}$ ); $J_{0}$ - the moment of inertia of the body relative to the axis of swing of the rotors $O_{1} ; c$-stiffness of the elastic element; $k$ - shock absorber coefficient; $L$ - installation distance of the suspension from the swing axis $O_{1} ; M_{G_{\mathrm{K}}}$ - moment of gravity of the body $G_{\mathrm{K}}$ relative to the axis of swing.

$$
M_{G_{K}}=G_{K} l_{H} \cos \gamma_{\kappa}+G_{K} l_{V} \sin \gamma_{K},
$$

where $l_{H}$, and $l_{V}$ - horizontal and vertical ordinates from the swing axis to the center of gravity of the body.

The moment of gravity of the body $G_{K}$ (Fig. 2) relative to the swing axis is found by the formula:

$$
\begin{gathered}
M_{G_{\mathrm{K}}}=G_{\mathrm{K}} \mathrm{L}, \\
M_{G_{\mathrm{K}}}=G_{\mathrm{K}} l_{H} \sin \gamma_{\mathrm{K}}-G_{\mathrm{K}} l_{V} \sin \gamma_{\mathrm{K}} \operatorname{tg} \gamma_{\mathrm{K}} .
\end{gathered}
$$

The angular movement of the body relative to the rotors is associated with the absolute angular movement of the body $\gamma_{K}$ and the angular movement of the rotors $\beta_{P}$ in the coordinates of the fixed reference system $X O Y$

$$
\gamma_{\kappa}=\varphi+\beta_{\mathrm{P}}
$$

Then

$$
\begin{gathered}
M_{G_{\mathrm{K}}}=G_{\mathrm{K}} l_{H} \sin \varphi \cos \beta_{\mathrm{P}}+G_{\mathrm{K}} l_{H} \cos \varphi \sin \beta_{\mathrm{P}}+ \\
+G_{\mathrm{K}} l_{V} \frac{\left(\sin \varphi \cos \beta_{\mathrm{P}}+\cos \varphi \sin \beta_{\mathrm{P}}\right)^{2}}{\left(\cos \varphi \cos \beta_{\mathrm{P}}-\sin \varphi \sin \beta_{\mathrm{P}}\right)}
\end{gathered}
$$


The value of the body angular movement relative to the body size is small, because the movement of the rotary-screw vehicle is considered in areas devoid of irregularities of considerable size. Therefore, it's possible to take:

$$
\sin \varphi \approx \varphi, \quad \cos \varphi \approx 1, \sin \beta_{\mathrm{P}} \approx \beta_{\mathrm{P}}, \quad \cos \beta_{\mathrm{P}} \approx 1,1-\beta_{\mathrm{P}} \varphi \approx 1,
$$

then the expression of the moment of gravity of the body $G_{\mathrm{K}}$ relative to the swing axis can be written:

$$
M_{G_{\mathrm{K}}}=G_{\mathrm{K}} l_{H} \varphi \cos \beta_{\mathrm{P}}+G_{\mathrm{K}} l_{H} \sin \beta_{\mathrm{P}}+G_{\mathrm{K}} l_{V} \varphi^{2}+2 G_{\mathrm{K}} l_{V} \varphi \beta_{\mathrm{P}}+G_{\mathrm{K}} l_{V} \beta_{\mathrm{P}}^{2} .
$$

After substituting this expression into equation (1), we finally get

$$
\ddot{\varphi}+R \dot{\varphi}+S \varphi-Q \beta_{\mathrm{P}} \varphi=A \beta_{\mathrm{P}}^{2}+B \beta_{\mathrm{P}},
$$

where

$$
R=\frac{k L^{2}}{J_{0}}, \quad S=\frac{c L^{2}-G_{\mathrm{K}} l_{H}}{J_{0}}, \quad A=\frac{G_{\mathrm{K}} l_{V}}{J_{0}}, \quad B=\frac{G_{\mathrm{K}} l_{H}}{J_{0}}, Q=\frac{2 G_{\mathrm{K}} l_{V}}{J_{0}} .
$$

The resulting linear inhomogeneous differential equation of the second order is transformed into a system of two differential equations of the first order

$$
\begin{aligned}
& \dot{\varphi}_{1}=\varphi_{2} ; \\
& \dot{\varphi}_{2}=-R \varphi_{2}-S \varphi_{1}+Q \beta_{\mathrm{P}} \varphi_{1}+A \beta_{\mathrm{P}}^{2}+B \beta_{\mathrm{P}},
\end{aligned}
$$

The system is solved by the Runge-Kutta numerical method.

The result of the solution is the dependence of the angular displacement and the velocity of the body relative to the rotors on the time - $\varphi(t), \dot{\varphi}(t)$, and the calculated acceleration $\ddot{\varphi}(t)$. found.

In the following, angular displacement, velocity and acceleration of the body can be

$$
\dot{\gamma}_{K}=\dot{\beta}_{\mathrm{P}}+\dot{\varphi}, \quad \ddot{\gamma}_{K}=\ddot{\beta}_{\mathrm{P}}+\ddot{\varphi}
$$

Then, on the basis of (8), the equation of the own (free) oscillations of the machine body at $\beta_{\mathrm{P}}=0$ can be written:

$$
\ddot{\varphi}+R \dot{\varphi}+S \varphi=0
$$

natural frequency of relative angular oscillations of the body:

or substituting $\mathrm{S}$ and $\mathrm{R}$ we get:

$$
\omega_{0}=\left(S-0,25 R^{2}\right)^{0,5}
$$

$$
\omega_{0}=\left[\left(c L^{2}-G_{K} l_{H}\right) J_{0}^{-1}-0,25 J_{0}^{-2} k^{2} L^{4}\right]^{0,5} .
$$

A real solution to this equation exists for $S>r$.

An increase in smoothness is movement is possible if the natural frequency of the structures does not coincide with the prevailing perturbation frequencies and is outside the range of oscillations unfavorable for the human body. Achieve this with change of $G_{\mathrm{K}}, l_{H}$ or $J_{0}$ is difficult, because these parameters are determined by technological processes for which the vehicle is designed. However, the stiffness of the elastic element $c$, the drag coefficient $k$ and the installation location of the suspension $L_{\Pi}$ (distances from the axis of swing to the suspension) can vary over a wide range. At the next stage of the research, the influence of the body and suspension parameters on the natural frequency will be considered.

The relative vertical movement of the rotors and the body can be expressed through the relative angular displacement. After substitution of the resulting expressions in the expression (8) we will get the proof that mutual angular and vertical oscillations have the same natural frequency. Therefore, for the frequency analysis of the transfer function, it is sufficient to use one type of oscillation. 
Then, based on the angular displacement we calculate the vertical displacement of the body gravity center. If the coordinates of the center of gravity and the angle of inclination are known, the coordinates of any point of the vehicle can be calculated.

The previously obtained values of the vertical displacement of the rotors gravity center $Y_{\text {ЦТ }}^{\mathrm{P}}$ and the rotors angular displacement $\beta_{\mathrm{P}}$ will be represented as the input of the dynamic rotor-body system whose output is the displacement (acceleration) of the body.

\section{Results.}

The obtained research results were applied in practice in the form of the prototype of the rotary-screw all-terrain vehicle with active suspension system. Полученные результаты исследований позволили разработать и применить на практике The works were carried out as part of the federal target program "Research and development in priority areas of development of the scientific and technological complex of Russia for 2014-2020" No. 14.577.21.0222 on the topic "Creating an experimental model of an amphibious autonomous transport and technological complex with intelligent control and navigation system for yearround reconnaissance drilling on the Arctic shelf". Patent purity of these decisions is confirmed by registered utility models № RU 516990 U1 и RU 15185 U1 [17,18,19]. Figure 3 presents the general view of the vehicle.

The results of the tests indicate that increasing the height of the snow has little effect on the power distribution over frequencies. When the height of snow changes from 0.3 to $0.6 \mathrm{~m}$, and from 0.6 to $1.0 \mathrm{~m}$, the redistribution of power between the peaks at medium and high frequencies is about $14 \%$.

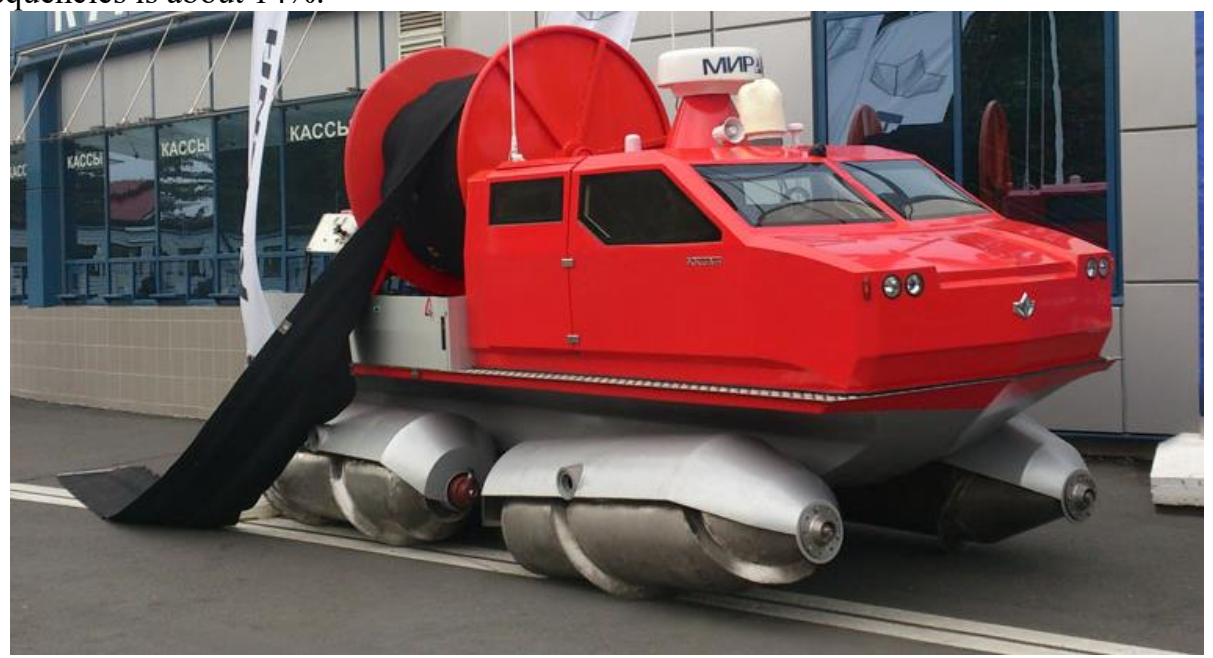

Fig. 3. Realized concept of the active suspension system

Increasing the snow height to a greater extent reduces the amplitude over the entire frequency range - the peak power at medium frequencies decreases by a factor of 5 as the average height of the snow increases from 0.3 to 0.6 and 1.5 times with an increase from 0.6 to 1.0 ; peak power at high frequencies, respectively -4.2 and 1.8 times. In such way, the choice of the motion route will play a great role for smooth running during relocation of the rotary-screw vehicles from one object to another. In this case, the magnitude of the accelerations (the amplitude of the spectrum) with increasing snow depth changes more than the frequency composition of the accelerations. 
For the generality of the results in the calculations, the angular displacement was taken to consist of a static value corresponding to the initial deformation of the elastic element under the action of body gravity $\varphi_{\mathrm{cT}}$ and the dynamic component, changing during movement $\varphi_{\text {д }}(t)$.

$$
\varphi(t)=\varphi_{\mathrm{cт}}+\varphi_{\text {д }}(t) .
$$

The presence of a time-independent quantity $\varphi_{\mathrm{cT}}$ gives the spectrum a component with a multiplier $f^{-1}$, where $f$ - the frequency. It explains the increase in the spectral densities of the accelerations of the body at the near-zero frequency.

From the data obtained, we can conclude that as the suspension stiffness decreases, the peak of the transfer function shifts to the left, and with the suspension stiffness $39,2 \times 10^{3} \mathrm{~N} / \mathrm{m}$ becomes zero $\left(\omega_{0}=0\right)$. At the same time in the last expression:

$$
\left(c L^{2}-G_{K} l_{H}\right) J_{0}^{-1}=0,25 J_{0}^{-2} k^{2} L^{4} .
$$

In this case, the module transfer function is equal to 1 , the suspension is blocked by a shock absorber, the rotors and the vehicle body oscillate as one body. A similar phenomenon (suspension blocking) occurs at high resistances of shock absorbers.

The result of the developed mathematical model is determination of the displacement, speed and acceleration of the rotary-screw vehicle body, which served as the basis for developing recommendations for the rotary-screw vehicle design.

\section{Conclusion.}

Performed according to the method, studies of oscillations and smoothness of the rotaryscrew vehicles, taking into account the regulatory requirements given in $[20,21]$ are presented in Figure 4. The figure shows the height of the snow and the speed of movement at which the mean square value of the vertical accelerations of the center of gravity will be on the border of the zone of negative influence on the human body (boundary of the warning zone, according to GOST 31191.1-2004 (ISO 2631-1: 1997 [20]). The obtained results do not contradict other regulatory documents governing the level of vibration exposure in humans [21-24].

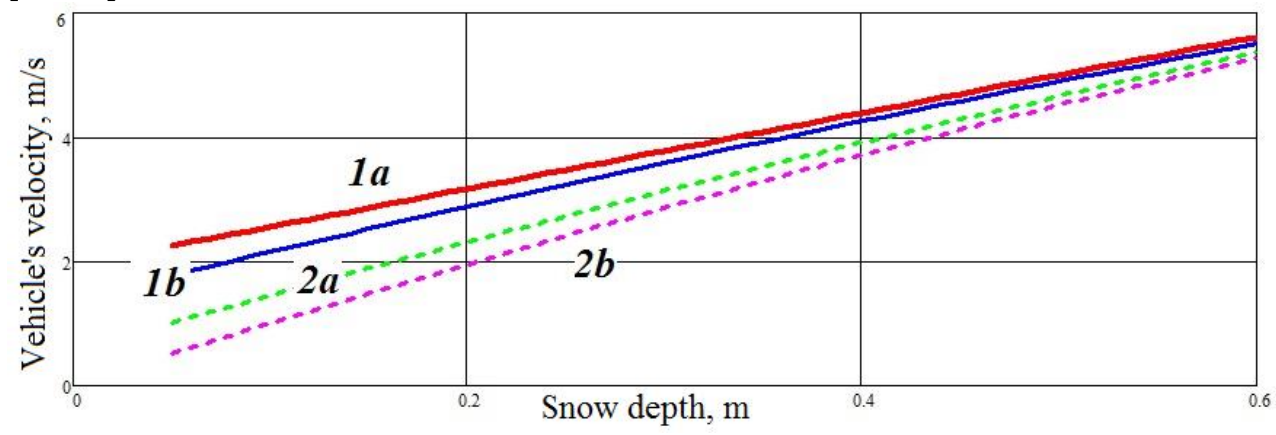

Fig. 4. Dependence of the limiting speeds of the rotary-screw vehicle on the average snow height. Where: 1a- movement of a vehicle with suspension over a rough terrain; $1 \mathrm{~b}$ - movement of a vehicle with suspension over rugged terrain; $2 \mathrm{a}$ - movement of a vehicle without suspension over a rough terrain; $2 b$ - movement of a vehicle without suspension over rugged terrain.

The evaluation of the motion smoothness showed that by installing the suspension, it is possible: to provide a level of comfort when driving on certain types of snow-covered terrain; 
increase the speed limit to ensure the performance of work in $1.5 \ldots 2.5$ times, depending on the conditions of movement on snowy terrain. This work is a continuation of scientific research conducted in the Nizhny Novgorod scientific school of all-terrain vehicles and the scientific school of BMSTU in recent years [25-28].

\section{References}

1. V. Makarov, D. Zeziulin, V. Belyakov, Prediction of all-terrain vehicles mobility in snowscape scenes, in International Conference of the International Society for TerrainVehicle Systems, ISTVS 2014; Convention Center, Hoam Faculty House, Seoul National University, Seoul; South Korea; 22 September 2014 through 25 September 2014; Code 111443 (2014)

2. V. Belyakov, A. Kurkin, V. Makarov, D. Zeziulin, Multifunctional vehicle for coastal areas, in The Twelfth International Conference on the Mediterranear Coastal Environment (MEDCOAST 2015) 06-10 October 2015, Varna, Bulgaria, p. 945-951 ISBN 978-605-85652-3-4 (ISBN 978-605-85652-4-2) (2015)

3. V. Belyakov, A. Kurkin, V. Makarov, D. Zeziulin, D. Minaev, A. Zaytsev, D. Teslenko, Ground vehicle for ice conditions monitoring, in Proceedings of the Thirteenth International MEDCOAST Congress on Coastal and Marine Sciences, Engineering, Management and Conservation, MEDCOAST 2017, 31 October - 4 November 2017, 2017, Mellieha, Malta, E. Ozhan (Editor) p. 775-785 ISBN 978-605-85652-6-5 (ISBN 978-605-85652-8-9) (2017)

4. P. Zvyagin, A. Voitkunskaia, Model of transit transport in arctic based on graph algorithms, in Proceedings of the International Conference on Offshore Mechanics and Arctic Engineering - OMAE 8, V008T07A002 (2016)

5. M. Krasheninnikov, A. Kulashov, V. Shapkin, A. Koshurina, The concept and methodology of creating the universal life-saver with rotary-screw mover, Lecture Notes in Electrical Engineering, in «Proceedings of the FISITA 2012 World Automotive Congress» 7, 195 (2013)

6. M. Krasheninnikov, A. Koshurina, I. Vasilyev, E. Smirnova, Procedia Engineering 100, 1242-1246 (2015)

7. J.V. Korushova, M.S. Krasheninnikov, A.A. Koshurina, D.A. Lyakhmanov, IOP Conf. Ser.: Mater. Sci. Eng. 393, 012119 (2018)

8. V.V. Belyakov, A.A. Kurkin, Road bed of transport-technology machines: tutorial (NNSTU, N.Novgorod, 2014)

9. V.V.Belyakov, A.P. Kulyashov, All-terrain transport and technological machines. Fundamentals of the theory of motion (TALAM, N.Novgorod, 2004)

10. A.P. Kulyashov, I.G. Kuklina, Construction and road machines 7, 45 (2011)

11. V. Elistratov, R. Denisov, Justification of wind turbine operation and management modes for Russian arctic conditions, in Proceedings of the 2017 International Conference on Industrial Engineering, Applications and Manufacturing, ICIEAM 2017, 8076219 (2017)

12. P. Zvyagin, A. Dobrodeev, K. Sazonov, Ice loads dynamics for model scale cylinders of various diameters, in Proceedings of the International Conference on Port and Ocean Engineering under Arctic Conditions, POAC (2017)

13. U.Sh. Vahidov, A.V. Sogin, V.A. Shapkin, Yu.V. Shapkina, Numerical studies of vehicle node vibrations, Trudy NGTU im. R.E.Alekseeva 3(105), 145-153 (2014) 
14. U.Sh. Vahidov, A.G. Kitov, A.V. Sogin, V.A. Shapkin, Yu.V. Shapkina, Parameters of noise and vibration of transport and technological machines, Mezhdunarodnyj zhurnal prikladnyh i fundamental'nyh issledovanij 7, 8-11 (2014)

15. I.A. Erasov, Yu.I. Molev, D.S. Mokerov, T.G. Shetulova, IOP Conf. Ser.: Mater. Sci. Eng. 386, 012006 (2018)

16. V.V. Yeliseyev, Dynamics, critical speeds and balancing of thermoelastic rotors, in Lecture Notes in Mechanical Engineering 22, 129-136 (2015)

17. Patent of the Russian Federation for utility model № RU 15185 U1, 03.04.2000

18. Patent of the Russian Federation for utility model № RU 156990 U1, 31.08.2015

19. A.A. Koshurina, M.S. Krasheninnikov, R.A. Dorofeev, Procedia Engineering 150, 1263 1269 (2016)

20. ISO 2041:2009 Mechanical vibration, shock and condition monitoring — Vocabulary - Third Edition

21. Mechanical vibration - Testing of mobile machinery in order to determine the vibration emission value; German version EN 1032:2003

22. ISO 2631-1:1997 Mechanical vibration and shock - Evaluation of human exposure to whole-body vibration - Part 1: General requirements (MOD).

23. ISO 5349-1:2001 Vibration. Measurement and evaluation of human exposure to handtransmitted vibration. Part 1 . General requirements

24. ISO 5349-2:2001 Vibration. Measurement and evaluation of human exposure to handtransmitted vibration. Part 2.Requirements for measurement at the workplace

25. V Klubnichkin, E Klubnichkin, G Kotiev, S Beketov, V Makarov, IOP Conference Series: Materials Science and Engineering 386, 012016 (2018)

26. D. Tyugin, D. Zeziulin, A. Kurkin,V. Belyakov, V. Makarov, IOP Conference Series: Materials Science and Engineering 386, 012009 (2018)

27. A. Papunin,V. Belyakov, V. Makarov, A. Anikin, U. Vahidov, IOP Conference Series: Materials Science and Engineering 386, 012001 (2018)

28. E. Klubnichkin, V. Klubnichkin, G. Kotiev, IOP Conference Series: Materials Science and Engineering 386, 012025 (2018) 